\title{
Sustainable Clinical Academic Training Pathways A framework for implementation in Oman
}

"Ibrahim S. Al-Busaidi' and Rashid A. Al-Mandhari²

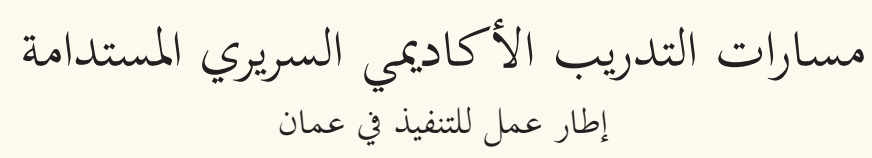

إبراهيم صالح البوسعيدي وراشد عبد اله المنذري

ABSTRACT: Clinical academics-medical doctors with additional training in basic science or clinical researchplay a pivotal role in translating biomedical research into practical bedside applications. However, international studies suggest that the proportion of clinical academics relative to the medical workforce is dwindling worldwide. Although efforts to reverse this trend are ongoing in many countries, there is little perceptible dialogue concerning these issues in Oman. This article explores the current status of clinical academic training pathways worldwide, concluding with a framework for the implementation of a dual-degree medical-research training programme in Oman in order to stimulate and develop a sustainable national clinical academic workforce.

Keywords: Training Programs; Undergraduate Medical Education; Graduate Medical Education; Internship and Residency; Medical Students; Research; Oman.

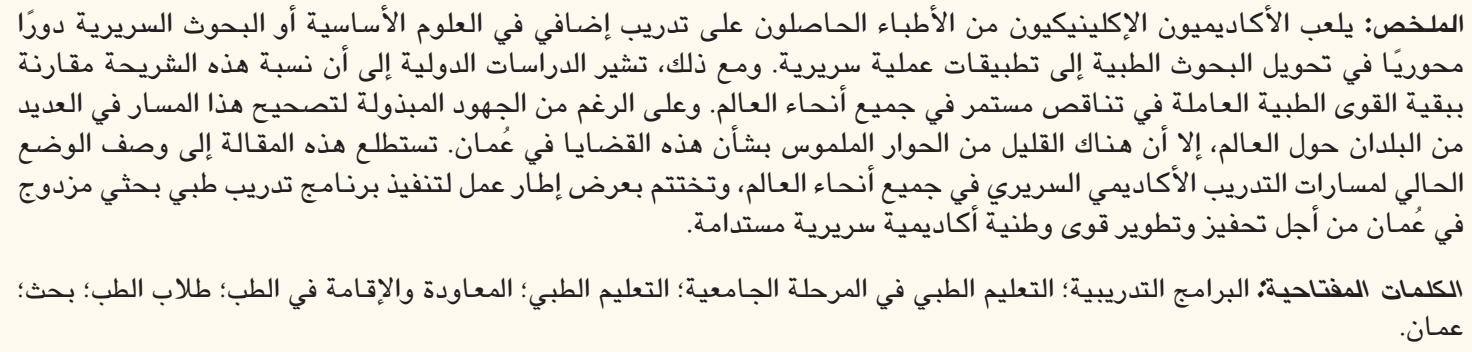

$\mathrm{C}$ NUOUS MEDICAL RESEARCH IS ESSENTIAL for the generation of new knowledge and the development of high-quality and evidencebased clinical practice. ${ }^{1}$ Also known as clinicianscientists, clinical academics are medical doctors who have received further training in basic science or clinical research. By virtue of their combined experience in patient care and research, these professionals play a pivotal role in converting biomedical research into practical applications to clinical care. ${ }^{1,2}$ However, global reports point towards a gradual decline in the clinical academic workforce, for instance in North America, the UK, Europe, New Zealand and Australia. ${ }^{2-6}$ In many cases, clinicians are disinclined to pursue training in order to establish careers as clinical academics due to a lack of research training pathways, appropriate mentorship and funding. ${ }^{6,7}$

The importance of developing sustainable clinical academic training pathways has been recognised since the mid-20 ${ }^{\text {th }}$ century. ${ }^{1,2}$ In the USA, the gradual decline in the clinical academic workforce prompted the establishment of programmes combining research training with medical education. ${ }^{8}$ Since then, other countries have similarly introduced different types of programmes in order to bridge this gap in the workforce. ${ }^{9-13}$ However, while many countries have made efforts to understand and address this trend, issues related to the clinical academic workforce in Oman have remained largely unexplored. Published articles on the subject are scarce and there is as yet no consolidated source of information available to describe Omani clinical academic training pathways and their outcomes.

As such, the purpose of this paper was to ignite interest in clinical academic training programmes among governmental agencies, educators and students in Oman. This article sheds light on existing pathways around the world which provide research training opportunities alongside clinical training. It also explores the status of these pathways and concludes 
with a suggested framework for the development of a sustainable clinical academic workforce in Oman.

\section{Global Clinical Academic Training Programmes}

An examination of the structure and outcomes of the main training pathways offered across the globe is an important initial step to developing a successful research training programme in Oman, as it can help to identify potential barriers or obstacles prior to implementation. Examples of various training pathways available globally are presented in Table 1.,14-19

\section{DUAL MEDICAL-DOCTOR OF PHILOSOPHY PROGRAMMES}

A dual medical-Doctor of Philosophy (PhD) programme is a structured pathway which offers students the opportunity to combine their medical training (i.e. a Doctor of Medicine [MD] degree) with a research-based degree (i.e. a PhD). ${ }^{9-12,20}$ In 1956, the Case Western Reserve University School of Medicine in the USA introduced the first combined MD-PhD programme, with the MD considered a postgraduate degree in the USA. ${ }^{21}$ Since then, the number of dual $\mathrm{MD}-\mathrm{PhD}$ programmes has continued to increase; according to a recent estimate, they are offered in $85 \%$ of medical schools across the USA. ${ }^{20}$ This pathway has also rapidly grown in popularity elsewhere around the globe, with programmes established in both developed and developing countries including Canada, the UK, Europe, Australia, New Zealand and South Africa. ${ }^{9-13}$

Although they share the common objective of producing independent researchers, dual-degree programmes often vary in terms of curriculum design, admission model (i.e. undergraduate versus postgraduate entry), selection criteria, funding sources (i.e. government versus private bodies/universities) and graduation requirements. They are typically offered to a highly selective group of motivated and academically exceptional students and span 6-10 years, with the $\mathrm{PhD}$ portion of the programme sandwiched between the preclinical and clinical years. ${ }^{9-12,20}$

Overall, a dual medical-PhD programme is the most well-established and successful pathway for producing a sustainable and productive clinical academic workforce. ${ }^{10,20}$ Previous studies indicate that most dualdegree medical-PhD graduates continue to pursue further training in research, secure academic posts and obtain research grants following graduation. ${ }^{10,20,22}$ In addition, according to a report by the National Institutes of Health in the USA, these graduates were more successful in obtaining competitive research grants compared to those holding single degrees or either degree alone. ${ }^{14}$

Despite their success, combined medical-PhD programmes have faced various setbacks. In a study of 24 dual MD-PhD programmes, Brass et al. observed that the level of interest in intercalated research degrees among medical students was decreasing with time, with an average attrition rate of $10 \%$; moreover, between 1965-2007, more research-oriented residency choices like internal medicine, neurology, pathology and paediatrics declined in popularity. ${ }^{22}$ Suggested barriers to entering and/or completing a dual-degree $\mathrm{MD}-\mathrm{PhD}$ programme include the lengthy training period, poor mentorship and a lack of funding. ${ }^{20,22,23}$

\section{CLINICIAN INVESTIGATOR PROGRAMMES}

In Canada, the first clinical investigator programme (CIP) was developed in 1995..$^{1724}$ Unlike the MD$\mathrm{PhD}$ pathway, CIPs are aimed at the postgraduate/ resident level and comprise a minimum of two years of condensed and structured research training courses. ${ }^{24}$ Although initially both non-degree and graduate degree options were provided, only graduate degree options have been offered since 2008, leading to a master's degree at minimum, with a PhD degree also available. ${ }^{24}$

Table 1: Examples of global clinical academic research training programmes ${ }^{9,14-19}$

\begin{tabular}{|c|c|c|}
\hline Type of pathway & Example & Duration \\
\hline $\begin{array}{l}\text { Intercalated/concurrent medical- } \\
\text { research degrees }\end{array}$ & $\begin{array}{l}\text { - MD-PhD programmes backed by the National Institute of Health in the } \\
\text { USA }^{14} \\
\text { - The Clinician-Scientist Track in Australia }{ }^{15} \\
\text { - The MD-MPH programme at the University of North Carolina at Chapel } \\
\text { Hill in the USA }{ }^{16} \\
\text { - The MB ChB-BMedSc(Hons) programme at the University of Auckland } \\
\text { and University of Otago in New Zealand }{ }^{9}\end{array}$ & $1-3$ years \\
\hline Postgraduate/residency-level tracks & - The Clinician Investigator Programme in Canada ${ }^{17}$ & $2-3$ years \\
\hline $\begin{array}{l}\text { PhD-to-medical degree } \\
\text { programmes }\end{array}$ & - The PhD-to-MD programme at the University of Miami in the USA ${ }^{18}$ & $2-3$ years \\
\hline $\begin{array}{l}\text { Formal extracurricular } \\
\text { opportunities }\end{array}$ & $\begin{array}{l}\text {-The Summer Studentship programme at the University of Otago in New } \\
\text { Zealand }^{19}\end{array}$ & 10 weeks \\
\hline
\end{tabular}


Residents may select from three different CIP pathways to integrate their postgraduate medical training. The continuous pathway provides uninterrupted intensive research training during a minimum of 24 months. ${ }^{24}$ In the distributive pathway-offered only to outstanding residents with prior research experience-postgraduate first-year residents gain entry to both residency training and the CIP. Finally, the fractionated pathway involves at least 24 months of research, of which 12 months can be undertaken in three-month blocks during clinical training with the addition of one year of continuous research training. ${ }^{24}$

In general, CIPs have been successful in attracting Canadian residents seeking academic or researchfocused careers. ${ }^{17,24,25}$ Residents enrolled in these programmes have benefited from multiple funding sources including universities, hospitals, the Canadian Ministry of Health, granting agencies and private funding foundations resulting in consistently low dropout rates. ${ }^{17,24}$ Statistics show that CIP residents publish an average of six peer-reviewed publications during their residency training, with approximately two-thirds (67\%) attaining academic positions following graduation. ${ }^{17,24}$

Nevertheless, CIPs are subject to similar challenges as those faced by $\mathrm{MD}-\mathrm{PhD}$ programmes in the USA..$^{22,24,25}$ Moreover, governmental funding for Canadian clinical academic training programmes was recently cut due to budgetary constraints. ${ }^{26}$ This move has been met by much astonishment and protest within the medical education community, both in Canada and worldwide. 10,26,27

\section{THE CLINICIAN-SCIENTIST TRACK}

The Clinician-Scientist Track (CST) in Australia was developed by the University of Queensland in 2010 to address the decline in medical students pursuing intercalated medical/research degrees. ${ }^{15}$ Unlike strict intercalated programmes, the CST provides the opportunity for outstanding students to enrol in a parttime master's or PhD degree that is either concurrent or intercalated with their medical degree. Funding is provided by the Australian Government, along with a scholarship from the University of Queensland's Graduate School. ${ }^{15}$

The CST programme offers three separate training pathways, all of which culminate in a dual degree. ${ }^{15}$ The concurrent MD-master's pathway gives students the option of completing a research-focused master's degree on a part-time basis while continuing their MD training without disruption. In the intercalated MD-master's pathway, students undertake one year of full-time research after the second year of their MD course, with the master's degree subsequently being completed on a part-time basis. Finally, with the intercalated MD-PhD pathway, students interrupt their four-year MD training after the second year for two full-time years of $\mathrm{PhD}$ research, before finalising their $\mathrm{PhD}$ research projects during the remainder of their MD programme. ${ }^{15}$

Overall, the CST training pathway has been received with great enthusiasm by the students enrolled at the University of Queensland..$^{15}$ As of 2018, a total of 96 students had been enrolled in the pathway in the eight years since its inception, of which 36 had completed a dual MD-PhD degree, with $28 \%$ transferring from the master's to the $\mathrm{PhD}$ track; moreover, the overall attrition rate was $14 \%$, similar to those reported in other pathways. ${ }^{15,20,22}$ Furthermore, CST students reportedly published 159 journal papers and 112 conference abstracts between 2010 and 2016, with an average of 2.24 papers and 1.58 conference abstracts per student. ${ }^{15}$

\section{DOCTOR OF PHILOSOPHY-TO- DOCTOR OF MEDICINE PROGRAMMES}

In the USA and Canada, PhD-to-MD programmes offer $\mathrm{PhD}$ holders the opportunity to take an accelerated two- or three-year MD degree. ${ }^{28}$ Despite initial concern, no significant discrepancies have been observed in the clinical performance of graduates of expedited three-year degrees compared to those of the usual four-year medical training programmes. ${ }^{28}$ In fact, an evaluation of the two-year PhD-to-MD programme at the University of Miami in the USA found that the truncated training course was successful in producing accomplished clinical academics. ${ }^{18}$

\section{DOCTOR OF MEDICINE-MASTER OF PUBLIC HEALTH PROGRAMMES}

In the USA, the first formal MD-Master of Public Health (MPH) programme was developed at the University of North Carolina at Chapel Hill to address the lack of MPH degrees among medical graduates. ${ }^{16}$ In the early 1990s, MD-MPH programmes were offered in $25 \%$ of American medical schools; this subsequently increased to $60 \%$ by $2013 .{ }^{29}$ Various programmes were developed, most of which combine clinical training with research in public health-related topics over a five-year period. ${ }^{16}$

Since then, the dual-degree MD-MPH programme has gained traction in other developed and developing countries. ${ }^{30,31}$ According to a national cohort study conducted in the USA, graduates of MD-MPH programmes were reportedly not at a disadvantage in terms of student debt and were more likely to pursue primary care specialties (e.g. family medicine) and obtain appointments at academic centres. ${ }^{29}$ 


\section{BACHELOR OF MEDICAL SCIENCE WITH HONOURS}

A Bachelor of Medical Science with Honours (BMedSc[Hons]) is an intercalated research degree in New Zealand in which students interrupt their regular medical training (i.e. a Bachelor of Medicine and Bachelor of Surgery [MBChB] degree) to undertake a one-year full-time supervised research project. ${ }^{9}$ Academically outstanding students also have the opportunity to subsequently transfer to a $\mathrm{PhD}$ degree. This typically involves one additional year of full-time research incorporated between the preclinical and clinical years (i.e. two years of full-time research). ${ }^{9}$

According to recent studies, approximately one-third (33\%) of theses written by BMedSc(Hons) graduates were found to result in peer-reviewed journal publications. $^{32,33}$ However, while students generally report a high degree of satisfaction with this type of programme, a number of barriers exist including poor supervision, increased debt and delayed graduation. ${ }^{34}$

\section{SUMMER RESEARCH STUDENTSHIPS}

Studentships are a popular form of short-term supervised research experiences available to medical students in several countries.,19,35 Typically, students spend between 8-16 weeks of their summer vacation working on a research project., ${ }^{9,35}$ Short-term research projects provide students with a chance to meaningfully contribute to the mainstream medical literature, with research showing that approximately one-third of studentships result in subsequent peerreviewed publications. ${ }^{19,36}$

\section{OTHER PATHWAYS}

Other than the aforementioned medical dual-degree research programmes, a number of alternative training pathways are also available, such as MD-Juris Doctor, MD-Master of Business Administration, MDMaster of Mass Communication and MD-Master of Advanced Study in Health Informatics programmes, among others. ${ }^{37,38}$

\section{Framework for Implementation in Oman}

\section{CURRENT SITUATION}

From the beginning of the reign of the former ruler Sultan Qaboos bin Said in 1970, Oman has invested greatly in health services and medical research, as evidenced by successful efforts over the last two decades to control the burden of communicable and preventable diseases. ${ }^{39}$ In addition, the number of medical schools, academic centres and funding bodies has increased dramatically. ${ }^{39-41}$ In 1991, the Ministry of Health established the Centre of Studies and Research (CSR), previously known as the Directorate of Research and Studies, in order to support research development in Oman. ${ }^{39,41}$ The CSR is responsible for advising researchers, reviewing and approving research proposals, setting health research priorities and holding research training workshops. ${ }^{39}$

Other initiatives include the creation of research funding bodies (e.g. The Research Council) as well as postgraduate or higher academic qualification programmes in biomedical fields. ${ }^{39,40}$ In 2006, the Oman Medical Speciality Board (OMSB), a national body accredited by the Accreditation Council for Graduate Medical Education-International, was established to oversee graduate medical education in the country. ${ }^{42}$ All OMSB residency programmes include a structured research module and residents are expected to complete a research project from design to dissemination. ${ }^{43}$ These factors indicate that Oman has an infrastructure suitable for the development of future generations of researchers.

Unfortunately, recent reports indicate that Oman is not living up to its potential in terms of the quality and quantity of its medical research. ${ }^{44,45}$ Al-Maawali et al. reported promising trends in biomedical research in the Gulf Cooperative Council (GCC) region between 1970 and 2010; however, Oman was found to have the lowest research output after the results were normalised for population size. ${ }^{45}$ Moreover, Oman has the second lowest Hirsch index (an indicator of research productivity and impact) in medicine among all GCC countries and ranks $11^{\text {th }}$ among Middle Eastern countries and $81^{\text {st }}$ globally in terms of medical research output. ${ }^{46}$ According to a recent study, only $15 \%$ of primary healthcare professionals in Oman reported participating in clinical research, with poor mentorship, time constraints, funding and a lack of training and statistical support being the main barriers. ${ }^{47}$ Similarly, less than one-quarter (8-22.1\%) of research performed by OMSB residents has been found to result in peer-reviewed publications. ${ }^{43,48}$

The Health Vision 2050 initiative of the Ministry of Health aspires for Oman to be "a regional leader and a research hub of international standards", with collaboration between local and international academic institutions recognised as a key factor in strengthening the country's research capacity. ${ }^{39}$ However, although this mission acknowledges that establishing a career path for research-oriented professionals is an important factor in improving research quality and quantity, to the best of the authors' knowledge, no well-defined research training pathways have as yet been established in Oman. 


\section{Current Medical Programmes}

Currently, there are two medical schools in Oman, namely the College of Medicine and Health Sciences at Sultan Qaboos University (COMHS-SQU) and the College of Medicine and Health Sciences at the National University of Science \& Technology (COMHS-NU), formerly known as the Oman Medical College. ${ }^{49-52}$ However, neither medical school currently offers an intercalated medicine-research degree (e.g. a dual MD-master's or MD-PhD degree). ${ }^{50,52}$

SQU was established in 1986, with the COMHS forming one of its five constituent colleges; however, it was not until 2013 that the MD programme was fully accredited. ${ }^{49}$ The current MD programme at COMHSSQU is a six-year undergraduate degree divided into three phases. ${ }^{50,51}$ Phase I involves two semesters of various basic sciences and university-mandated courses (i.e. courses' requirements set by the university, regardless of choice of degree) over a one-year period. Subsequently, phase II incorporates clinical sciences, medical informatics, research teaching and experience and early medical contact over two years, while phase III consists of clinical clerkships and pre-internship experience which take place over three years. ${ }^{50,51}$

The primary objective of COMHS-SQU is to provide students with a supportive environment that encouragesresearch participation. ${ }^{50}$ Thisis evidentwithin the structure of the newly accredited MD programme; in phase II, students take part in a module entitled "Research Project Module" which spans three semesters and is dedicated to teaching research methods, design, ethics, critical appraisal, biostatistics and dissemination. Moreover, as part of this module, students are required to conduct a complete research study (either clinical or laboratory-based), from initial data collection and analysis to the dissemination of their findings via written reports and oral presentations. ${ }^{50}$

Historically, COMHS-SQU required all MD candidates to undertake a four-year Bachelor of Science in Health Sciences (BSc[HS]) degree as a prerequisite to a three-year MD degree, resulting in a seven-year undertaking. ${ }^{50}$ However, the current sixyear curriculum gives students the option of obtaining a $\mathrm{BSc}(\mathrm{HS})$ degree by taking part in an additional year (an intercalated phase) between phases II and III. ${ }^{50,51}$ Currently, the postgraduate research degrees offered to both MD and non-MD graduates at COMHS-SQU include a Master of Biomedical Sciences (offered since 2001 with six scholarships available annually) and a PhD (offered since 2009 with two scholarships available annually)..$^{50}$

In contrast, COMHS-NU offers a six-year undergraduate MD programme that consists of one year of pre-medical courses, three years of pre-clinical courses and two years of clinical courses. ${ }^{52}$ In the third year of the pre-clinical phase, students are required to complete two research-related courses entitled "Research Methodology and Project" and "Epidemiology, Public Health and Biostatistics". However, COMHS-NU does not offer any postgraduate degrees at present. ${ }^{52}$

\section{EXPERIENCE OF OMANI STUDENTS WITH CLINICAL ACADEMIC TRAINING PATHWAYS ABROAD}

It is instructive to reflect on the experience of Omani medical graduates who have explored clinical academic training pathways abroad. Since 2004, the Ministry of Higher Education has provided scholarships for Omani students to pursue undergraduate medical training (i.e. a $\mathrm{MBChB}$ programme) at the University of Otago and University of Auckland in New Zealand (verbal communication, Dr Hussain Al-Lawati). In New Zealand, medical degree programmes are similar to those in Oman, in that they last six years and consist of both pre-clinical and clinical phases. However, the $\mathrm{MBChB}$ degree at the University of Otago is structured somewhat differently. ${ }^{53}$

To begin with, students at the University of Otago take part in a one-year phase entitled "Health Sciences First Year", a competitive one-year course that determines admission to second year courses. ${ }^{53}$ Subsequently, they undergo a two-year phase known as "Early Learning in Medicine" involving a variety of pre-clinical courses including research education. The final three-year phase is titled "Advanced Learning in Medicine" and involves two years of clinical courses followed by one year as a trainee intern. ${ }^{53}$ The trainee internship is an apprenticeship-type course that comprises four 12week stages, of which three are research, hospital and community-based attachments and the remaining stage is a medical elective attachment. ${ }^{53}$

In addition, unlike the MD programmes offered in Oman, the $\mathrm{MBChB}$ programme at the University of Otago considers applications from candidates in the following three categories: Health Sciences First Year completionists (i.e. those who have successfully completed the competitive one-year phase), domestic graduates (i.e. those who have received a bachelor's degree from another university in New Zealand) and others (i.e. domestic students who have completed a master's or doctoral degree in New Zealand or those with health-related professional experience in a relevant field). ${ }^{53}$

In New Zealand, intercalated MBChB-research programmes offer students the opportunity to combine their medical training with a full-time research-based degree. ${ }^{9,32-34}$ Currently, two intercalated research degrees are offered: a BMedSc(Hons) degree, a one-year full- 
Table 2: Details of Omani students who have completed a research intercalated degree during medical undergraduate training in New Zealand $(\mathrm{N}=31)$

\begin{tabular}{|c|c|c|c|c|c|}
\hline \multirow[t]{3}{*}{ Gender } & \multicolumn{4}{|c|}{ n (\%) } & \multirow[t]{3}{*}{ Total } \\
\hline & \multicolumn{2}{|c|}{ University of Otago } & \multicolumn{2}{|c|}{ University of Auckland } & \\
\hline & $\operatorname{MBChB}(n=15)$ & $\mathrm{BMedSc}($ Hons $) / \mathrm{PhD}(\mathrm{n}=6 / 1)$ & $\operatorname{MBChB}(n=16)$ & BMedSc(Hons) $(\mathrm{n}=1)$ & \\
\hline Male & $9(60)$ & $5(71.4)$ & $5(31.3)$ & $1(100)$ & $14(45.2)$ \\
\hline Female & $6(40)$ & $2(28.6)$ & $11(68.8)$ & $0(0)$ & $17(54.8)$ \\
\hline
\end{tabular}

Traditional research training pathway

\begin{tabular}{|c|c|c|c|c|c|}
\hline P1-P2 & P3 & Inter & \multicolumn{2}{|c|}{ Residency/fellowship } & Master's/PhD \\
\hline \multicolumn{6}{|c|}{ Proposed research training pathway } \\
\hline P1-P2 & Master's/PhD & $P$ & Inter & Resi & ency/fellowship \\
\hline
\end{tabular}

Figure 1: Proposed framework for the integration of research training into medical education in Oman.

$P=$ phase; Inter = internship; $P h D=$ Doctor of Philosophy.

time supervised thesis-based degree completed after the third year of the MBChB course or a $\mathrm{PhD}$ degree, an eight-year degree offered to academically outstanding students. ${ }^{9}$ The former intercalated degree (i.e. MB ChB-BMedSc(Hons) is a seven-year course, while the latter requires a minimum of two years of dedicated research training in addition to the sixyear $\mathrm{MBChB}$ course. PhD-related work can also be completed during the summer holidays and a threemonth elective period as part of the final year (i.e. during the trainee internship) of the $\mathrm{MBChB}$ course. For both BMedSc(Hons) and $\mathrm{PhD}$ degrees, candidates are required to submit a thesis. ${ }^{9}$

As of December 2018, 31 Omani medical students have graduated with $\mathrm{MBChB}$ degrees from medical schools in New Zealand (verbal communication, Ms. Val Farmer). Of these, eight (25.8\%) were enrolled in intercalated research degrees, of which seven took part in BMedSc(Hons) programmes and one a $\mathrm{PhD}$ degree [Table 2]. While it is still too early to determine the long-term academic success of these graduates (i.e. whether they will go on to complete higher academic degrees or obtain university faculty positions), most of the dual-degree graduates have continued to be involved in research following graduation. A literature search of the PubMed ${ }^{\circledR}$ database (National Library of Medicine, Bethesda, Maryland, USA) in August 2019 indicated that five of the graduates (62.5\%) had authored at least one peer-reviewed publication after graduation, with 75 publications in total (range: 1-33 publications each; median time since graduation: 3.7 years).

\section{IMPLEMENTING A DUAL MEDICAL- RESEARCH PROGRAMME}

In light of the relatively high uptake of dual medicalresearch degrees by Omani students in New Zealand and their continued involvement in research after graduation, it seems likely that a similar research training programme might be of interest to medical students in Oman. However, given that formal pathways to integrate research and medical training are lacking, Omani medical students interested in a clinical academic career are currently obligated to pursue stand-alone postgraduate degrees after graduating from medical school. Unfortunately, this involves putting specialty training on hold and spending upwards of 2-6 years away from clinical practice, an approach that is unappealing to most medical students. ${ }^{9,33}$

As evidenced earlier, a dual-degree MD-PhD programme is the most popular, coordinated and well-established type of research training pathway. ${ }^{10,20}$ Although other degree programmes exist in Oman, there is an absence of programmes combining clinical training and research. With this in mind, the following framework is proposed for the development of an intercalated dual-degree MD-research programme at Omani medical schools. The programme should be offered to academically outstanding students interested in combining clinical practice and research. The intercalated research degree would include either a master's (involving one year of full-time research) and/or a $\mathrm{PhD}$ (comprising three years of full-time research). As a result, the suggested pathway would take between 7-9 years to complete [Figure 1]. 
It is hoped that this framework will help to develop and maintain the clinical academic workforce in Oman by attracting medical students committed to a career in both medicine and research. Possible barriers to implementing this programme are likely to be similar to those reported in other training pathways, such as dwindling interest in research among medical students, a high attrition rate, lack of availability of research infrastructure, lack of time among mentors/supervisors and inadequate

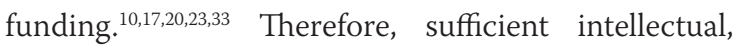
financial and administrative support is crucial for the success of this programme.

Several initiatives are required prior to the implementation of this framework. To begin with, studies should be undertaken to evaluate Omani medical students' interest in, attitudes towards and perceived barriers to a combined medical-research training programme. Secondly, it remains to be determined whether the OMSB has the capacity and resources necessary to provide research supervision and mentorship for dual-degree candidates. Thirdly, the perspective of policymakers at both COMHSSQU and COMHS-NU should be elicited, particularly as COMHS-SQU already offers medical students the option of intercalating a $\mathrm{BSc}(\mathrm{HS})$ degree with the sixyear MD programme. ${ }^{47,48}$ Nevertheless, it would be beneficial if an additional one-year supervised thesisbased research degree were to be offered to qualified medical students. Finally, it is imperative that sufficient funding be secured to support the implementation of a clinical academic training programme in Oman.

\section{Conclusion}

Parallel with the current MD programmes available, the establishment of an optional intercalated research degree programme in Oman would be invaluable to enhance the development of a sustainable and productive national clinical academic workforce. Hopefully, the framework described in this article will be of use in facilitating this initiative and sparking discussion on this important topic. The authors sincerely welcome any input from interested parties both in Oman and across the globe, from deans of medical schools to residency programme directors, university faculty members, clinical teachers, physicians, fellows, residents, trainees and medical students.

\section{CONFLICT OF INTEREST}

The authors declare no conflicts of interest.

\section{FUNDING}

No funding was received for this research.

\section{References}

1. Arias I. Training basic scientists to bridge the gap between basic science and its application to human disease. N Engl J Med 1989; 321:972-4. https://doi.org/10.1056/NEJM198910053211412.

2. Ley TJ, Rosenberg LE. The physician-scientist career pipeline in 2005: Build it, and they will come. JAMA 2005; 294:1343-51. https://doi.org/10.1001/jama.294.11.1343.

3. Fitzpatrick S. A survey of staffing levels of medical clinical academics in UK medical schools as at 31 July 2012: A report by the Medical Schools Council. From: www.medschools.ac.uk/ media/1248/2012-staffing-levels-of-medical-clinical-academicsin-uk-medical-schools-2012-data.pdf Accessed: Feb 2020.

4. Sheridan DJ. Reversing the decline of academic medicine in Europe. Lancet 2006; 367:1698-701. https://doi.org/10.1016/ S0140-6736(06)68739-4.

5. Windsor J, Garrod T, Talley NJ, Tebbutt C, Churchill J, Farmer E, et al. The clinical academic workforce in Australia and New Zealand: Report on the second binational summit to implement a sustainable training pathway. Intern Med J 2017; 47:394-9. https://doi.org/10.1111/imj.13356.

6. Lander B, Hanley GE, Atkinson-Grosjean J. Clinician-scientists in Canada: Barriers to career entry and progress. PloS One 2010; 5:e13168. https://doi.org/10.1371/journal.pone.0013168.

7. Milewicz DM, Lorenz RG, Dermody TS, Brass LF. Rescuing the physician-scientist workforce: The time for action is now. J Clin Invest 2015; 125:3742-7. https://doi.org/10.1172/JCI84170.

8. Mark AL, Kelch RP. Clinician scientist training program: A proposal for training medical students in clinical research. J Investig Med2001;49:486-90.https://doi.org/10.2310/6650.2001.33624.

9. Al-Busaidi IS, Wells CI. Stimulating the clinical academics of tomorrow: A survey of research opportunities for medical students in New Zealand. N Z Med J 2017; 130:80-8.

10. Skinnider MA, Squair JW, Twa DD, Ji JX, Kuzyk A, Wang X, et al. Characteristics and outcomes of Canadian MD/PhD program graduates: A cross-sectional survey. CMAJ Open 2017; 5:E308-14. https://doi.org/10.9778/cmajo.20160152.

11. Barnett-Vanes A, Ho G, Cox TM. Clinician-scientist MB/PhD training in the UK: A nationwide survey of medical school policy. BMJ Open 2015; 5:e09852. https://doi.org/10.1136/ bmjopen-2015-009852.

12. Power BD, White AJ, Sefton AJ. Research within a medical degree: The combined MB BS-PhD program at the University of Sydney. Med J Aust 2003; 179:614-16. https://doi.org/10.5694/j.1 326-5377.2003.tb05719.x

13. Katz AA, Futter M, Mayosi BM. The intercalated BSc (Med) Honours/MB ChB and integrated $\mathrm{MB} \mathrm{ChB} / \mathrm{PhD}$ tracks at the University of Cape Town: Models for a national medical student research training programme. S Afr Med J 2014; 104:111-13. https://doi.org/10.7196/samj.7639.

14. National Institutes of Health. Physician-scientist workforce (PSW) report 2014: Effects of early career NIH programs on physician-scientists with a medical degree. From: https:// report.nih.gov/workforce/psw/index.aspx Accessed: Feb 2020.

15. Eley DS. The Clinician-Scientist Track: An approach addressing Australia's need for a pathway to train its future clinical academic workforce. BMC Med Educ 2018; 18:227. https://doi. org/10.1186/s12909-018-1337-5.

16. Harris R, Kinsinger LS, Tolleson-Rinehart S, Viera AJ, Dent G. The MD-MPH program at the University of North Carolina at Chapel Hill. Acad Med 2008; 83:371-7. https://doi.org/10.1097/ ACM.0b013e318166a848. 
17. Hayward CP, Danoff D, Kennedy M, Lee AC, Brzezina S, Bond U. Clinician investigator training in Canada: A review. Clin Invest Med 2011; 34:E192. https://doi.org/10.25011/cim. v34i4.15360.

18. Koniaris LG, Cheung MC, Garrison G, Awad WM Jr, Zimmers TA. Perspective: $\mathrm{PhD}$ scientists completing medical school in two years - Looking at the Miami PhD-to-MD program alumni twenty years later. Acad Med 2010; 85:687-91. https://doi. org/10.1097/ACM.0b013e3181d296da.

19. Alamri Y, Currie W, Magner K, Al-Busaidi IS, Wilkinson TJ, Beckert L. Publication rates of, and attitudes toward, summer research projects: 10-year experience from a single institution in New Zealand. Adv Med Educ Pract 2019; 10:263-71. https:// doi.org/10.2147/AMEP.S198789.

20. Jeffe DB, Andriole DA, Wathington HD, Tai RH. Educational outcomes for students enrolled in MD-PhD programs at medical school matriculation, 1995-2000: A national cohort study. Acad Med 2014; 89:84-93. https://doi.org/10.1097/ ACM.0000000000000071.

21. Case Western Reserve University School of Medicine. Medical scientist training program: The original $\mathrm{MD} / \mathrm{PhD}$. From: https://case.edu/medicine/admissions-programs/md-phdprogram/ Accessed: Feb 2020.

22. Brass LF, Akabas MH, Burnley LD, Engman DM, Wiley CA, Andersen OS. Are MD-PhD programs meeting their goals? An analysis of career choices made by graduates of $24 \mathrm{MD}-\mathrm{PhD}$ programs. Acad Med 2010; 85:692-701. https://doi.org/10.1097/ ACM.0b013e3181d3ca17.

23. Kersbergen CJ, Bowen CJ, Dykema AG, Koretzky MO, Tang O, Beach MC. Student Perceptions of M.D.-Ph.D. Programs: A Qualitative Identification of Barriers Facing Prospective M.D.Ph.D. Applicants. Teach Learn Med 2020; 32:1-10.

24. Canadian Federation of Medical Students. Supporting clinicianscientist training in Canada. From: www.cfms.org/files/ position-papers/2016_supporting\%20clinician-scientist\%20 training\%20in\%20canada.pdf Accessed: Feb 2020.

25. Ballios BG, Rosenblum ND. Challenges facing physician scientist trainees: A survey of trainees in Canada's largest undergraduate and postgraduate programs in a single centre. Clin Invest Med 2014; 37:E268-83. https://doi.org/10.25011/ cim.v37i5.22008.

26. Twa DD, Squair JW, Skinnider MA, Ji JX. The Canadian clinician-scientist training program must be reinstated. J Clin Invest 2015; 125:4317-19. https://doi.org/10.1172/JCI85194.

27. Zhou TE, Savage PA, Eisenberg MJ. Canadian MD-Ph.D. programs produce impactful physician-scientists: The McGill experience. J Biomed Educ 2016; 2016:3836467. https://doi. org/10.1155/2016/3836467

28. Raymond JR Sr, Kerschner JE, Hueston WJ, Maurana CA. The merits and challenges of three-year medical school curricula: Time for an evidence-based discussion. Acad Med 2015; 90:1318-23. https://doi.org/10.1097/ACM.0000000000000862.

29. Andriole DA, Jeffe DB, Tai RH. Characteristics and career intentions of $\mathrm{MD}-\mathrm{MPH}$ program graduates: A national cohort study. Public Health Rep 2016; 131:637-49. https://doi. org/10.1177/0033354916662224.

30. Rowson M, Smith A, Hughes R, Johnson O, Maini A, Martin S, et al. The evolution of global health teaching in undergraduate medical curricula. Global Health 2012; 8:35. https://doi. org/10.1186/1744-8603-8-35

31. Manavi S, Nedjat S, Pasalar P, Majdzadeh R. What motivates talented medical students to study simultaneously at Master of Public Health (MPH)? Iran J Public Health 2013; 42:402-9.

32. Al-Busaidi IS, Alamri Y. Publication rates and characteristics of undergraduate medical theses in New Zealand. NZ Med J 2016; 129:46-51.
33. Al-Busaidi IS, Alamri Y, Wilkinson TJ. Successful publication by medical students in New Zealand: The role of clinical versus academic supervisors. N Z Med J 2017; 130:9-12.

34. Park SJ, Liang MM, Sherwin TT, McGhee CN. Completing an intercalated research degree during medical undergraduate training: Barriers, benefits and postgraduate career profiles. $\mathrm{N}$ Z Med J 2010; 123:24-33.

35. Patel S, Walsh CM, Udell JA. Exploring medically-related Canadian summer student research programs: A national cross-sectional survey study. BMC Med Educ 2019; 19:140. https://doi.org/10.1186/s12909-019-1577-z.

36. Wells CI, Wallace HB, McLaughlin SJ, Alexander HC, Shelling AN. Rate and predictors of publication by medical and health science summer research students: A 14-year analysis from Auckland, New Zealand. MedEdPublish 2016; 5:43. https://doi. org/10.15694/mep.2016.000129.

37. Mayo Clinic and Arizona State University. Dual Degrees. From: https://mayo.asu.edu/dualdegrees Accessed: Feb 2020.

38. Stanford Medicine. Dual-Degree Programs. From: http://med. stanford.edu/education/dual-degree-programs.html Accessed: Feb 2020.

39. AlMawali AH, AlQasmi AM, AlSabahiSM, Idikula J, Abd Elaty MA, Morsi M, et al. Oman Vision 2050 for health research: A strategic plan for the future based on the past and present experience. Oman Med J 2017; 32:86-96. https://doi.org/10.5001/ omj.2017.18.

40. Al-Shukaili A, Al-Maniri A. Writing a research proposal to The Research Council of Oman. Oman Med J 2017; 32:180-8. https://doi.org/10.5001/omj.2017.35.

41. United Nations Educational, Scientific and Cultural Organisation Cairo Office. Ethics and Law in Biomedicine and Genetics: An overview of national regulations in the Arab States. Cairo, Egypt: United Nations Education, 2011. P. 38.

42. Oman Medical Specialty Board. Resident manual. From: www.omsb.org/File_Publications/files 2016081409265 0801_491c9cb8-60ce-404f-97bc-bf1312b458be.pdf Accessed: Feb 2020.

43. Al-Busaidi IS, Al-Shaqsi SZ, Al Alawi AK, Al-Sinani S, Al-Kashmiri A. Characteristics, trends, and factors associated with publication among residents of Oman Medical Specialty Board programs. J Grad Med Educ 2019; 11:104-9. https://doi. org/10.4300/JGME-D-19-00259.

44. Rohra DK, Azam SI. Quantitative and qualitative analysis of PubMed-indexed biomedical publications in Oman from years 2005-2009. Oman Med J 2011; 26:160-5. https://doi. org/10.5001/omj.2011.39.

45. Al-Maawali A, Al Busadi A, Al-Adawi S. Biomedical publications profile and trends in Gulf Cooperation Council countries. Sultan Qaboos Univ Med J 2012; 12:41-7. https://doi.org/10.12 816/0003086.

46. SCImago Journal \& Country Rank. Country rankings: Middle East. From: www.scimagojr.com/countryrank.php?area=2700\& region=Middle\%20East\&order=h\&ord=desc Accessed: Feb 2020.

47. Jahan F, Al Maqbali A, Siddiqui MA, Al Zadjali NM. Attitude and barrier towards research amongst health care professionals working in primary care service of Oman. J Health Educ Res Dev 2015; 3:1000144. https://doi.org/10.4172/2380-5439.1000144.

48. Al-Busaidi IS, Dupo JU. Rate and predictors of publication of resident abstracts presented at Oman Medical Specialty Board scientific meetings. Sultan Qaboos Univ Med J 2018; 18:e501-6. https://doi.org/10.18295/squmj.2018.18.04.012.

49. Albarwani S, Al-Saadoon M, Al-Rawas O, Al-Yaarubi S, Al-Abri R, Al-Lamki L, et al. Accrediting the MD programme in Sultan Qaboos University: Process, earned benefits, and lessons learned. Health Prof Educ 2015; 1:50-7. https://doi. org//10.1016/j.hpe.2015.11.011. 
50. Sultan Qaboos University College of Medicine and Health Sciences. MD programme self study. From: http://web.squ.edu. om/med/Accreditation/SelfStudy2012_2013.pdf Accessed: Feb 2020 .

51. Burney IA. The curriculum at the College of Medicine and Health Sciences, Sultan Qaboos University. From: www.squ. edu.om/Portals/6/Orientation\%20_Ikram.pptx Accessed: Feb 2020.
52. National University of Science and Technology College of Medicine and Health Sciences. About College of Medicine. From: www.nu.edu.om/cm/deptcontent.aspx?id=304 Accessed: Feb 2020.

53. University of Otago. The Otago medical degree: Bachelor of Medicine and Bachelor of Surgery (MB ChB) - Programme information. From: www.otago.ac.nz/medicine/about/program me-structure/index.html Accessed: Feb 2020. 